\title{
Correlation between Cervical Vestibular Evoked Miogenic Potential (C-VEMP) and Hearing Loss Degree in Patients with Meniere's Disease
}

\author{
Lilian Felipe ${ }^{1 *}$, Herman Kingma ${ }^{2}$, Denise Utsch Goncalves ${ }^{3}$ and Marco Aurelio Rocha Santos ${ }^{3}$ \\ ${ }^{1}$ Fluminense Federal University- Rio de Janeiro, South America \\ ${ }^{2}$ Maastricht University, Europe \\ ${ }^{3}$ Minas Gerais Federal University - Minas Gerais, South America
}

Submission: December 15, 2016; Published: January 05, 2017

*Corresponding author: Lilian Felipe, Fluminense Federal University- Rio de Janeiro, Brazil, Coordinator of Speech Pathologist and Hearing Sciences, R. Dr. Silvio Henrique Braune, 22, Nova Friburgo - RJ, 28625-650, Brazil, South America, Email: lilianfelipe@id.uff.br

\begin{abstract}
Introduction: Ménière's disease (MD) is an idiopathic syndrome characterized by recurrent vertigo, hearing loss and tinnitus. The diagnostic is usually based on the patient's subjective symptoms, such as episodes of vertigo and hearing loss, or physical examination. Hydrops occurs most often in the cochlea, with the saccule as the second most frequent site for endolymphatic hydrops. The cervical vestibular evoked myogenic potential (c- VEMP) test is used in addition to the traditional testing to assess the vestibular system, and provides information about the saccule and inferior vestibular nerve.
\end{abstract}

Main: to find the clinical value of c-VEMP in MD correlating the audiometry and c-VEMP results.

Methods: participants selected should have unilateral involvement and definite MD, evaluated by auditory and vestibular functional tests. The criterion for inclusion in the study was altered EcoG at the affected side. C-VEMP was recorded unilaterally at the sternocleidomastoid muscle. Surface electromyographic activity was recorded ipsilaterally, while the patient was instructed to keep lateral head -turning absolutely in sitting position. The other reference and ground electrodes were separately set on the sternum and forehead. The short tone burst $(118 \mathrm{~dB} \mathrm{HL}$, $1000 \mathrm{~Hz}, 200$ times per stimulus) was conducted to the unilateral ear through a supra aural headphones.

Results: There were 30 normal-hearing volunteers (17 men and 13 women; age range 23-65 years, mean 30 years). The study population consisted of 42 patients with unilateral involvement of MD. For the MD group, the c-VEMP mean values were: $P 13=15.85 \mathrm{~ms}( \pm 0.6), \mathrm{N} 23=23.8 \mathrm{~ms}$ $( \pm 0.38)$; the average asymmetry index was $27.6 \%$. Normal c-VEMP responses were recorded in $25(59.5 \%)$ patients with DM. Abnormal c-VEMP was recorded in 17 (40.5\%). All abnormal responses were found at the same side of the EcoG alteration and hearing loss. From the normal hearing side, c-VEMP abnormalities were not found in all variable, comparing to the control group ( $p>0.05)$. The hearing loss stage influenced the number of alterations at the $\mathrm{c}$ - VEMP $(\mathrm{p}<0.05)$.

Conclusion: c-VEMP parameters have an important clinical role in MD and would be a useful method for assessing clinical severity or progression of MD, providing complementary information to that obtained by other diagnostic methods.

Abbreviations: SCM: Sternocleidomastoid; MRI: Magnetic Resonance Imaging; EMG: Electromyograms; c-VEMP: cervical Vestibular Evoked Myogenic Potential; EH: Endolymphatic Hydrops; AAO-HNS: American Academy of Otolaryngology-Head and Neck Surgery; MD: Ménière's Disease

\section{Introduction}

Ménière's disease (MD) is an idiopathic syndrome characterized by recurrent vertigo, hearing loss and tinnitus [13]. The cause is the endolymphatic hydrops (EH), which is the distension of the endolymphatic space. Apart from the cochlea, the saccule is the second most frequently affected site for hydrops [4-6]. The diagnostic is usually based on the patient's subjective symptoms, such as episodes of vertigo and hearing loss, or physical examination. The audiology and vestibular evaluation bring support to the clinical investigation [7]. In 1995, the American Academy of Otolaryngology-Head and Neck Surgery (AAO-HNS) proposed diagnostic criteria for MD and a staging system based on hearing function measured by pure tone threshold at $0.5,1.0$, 
2.0, and $3.0 \mathrm{kHz}$ [6]. Using the worst results during the 6-month period before treatment, stage I-IV have a four-tone average of $<26 \mathrm{~dB}, 26-40 \mathrm{~dB}, 41-70 \mathrm{~dB}$, and $>70 \mathrm{~dB}$. Clinically, fluctuating hearing loss plays a decisive role in the diagnosis of Ménière's disease, because endolymphatic hydrops occurs most often in the cochlear part.

Low-frequency hearing loss is common in the early stage of Ménière's disease. Over time, high frequency hearing is also affected. The EcoG is known to be a test with a high specificity for definite Ménière's disease, especially in cochlear MD [8-11]. The cervical Vestibular Evoked Myogenic Potential (c-VEMP) is an inhibitory sacculocollic reflex that includes the saccular macula, the inferior vestibular nerve and vestibulospinal tract. It is a noninvasive, well-tolerated, relatively simple test, first described by Colebatch and Halmagyi (1992). They are short latency electromyograms (EMG), evoked by loud acoustic stimuli and recorded using surface electrodes over the tonically contracted sternocleidomastoid (SCM) muscle [12-15]. Also recent advances in magnetic resonance imaging (MRI) techniques, with increasing magnetic field strength and technical developments of various imaging sequences, have enabled visualization of the delicate anatomy of the inner ear structures [12,16-18]. The purpose of the current study was to correlate the audiometry and c-VEMP results.

\section{Materials and Methods}

\section{Population}

Forty-two patients with unilateral involvement and definite $\mathrm{MD}$, according to the diagnostic criteria proposed by the AAOHNS, were evaluated by auditory and vestibular functional tests (PTA, EcoG, and c-VEMP). The criterion for inclusion in the study was altered EcoG at the affected side. Patients with neurological or musculoskeletal signs or symptoms and conductive hearing loss were excluded of the study. Informed consent was obtained from all participants. The Institutional Ethical Committee at our institution approved this study.

\section{Study designn}

Tonal and speech audiometry was performed using the twochannel audiometer AC 40 Clinical Audiometer (Interacoustics, AN, Denmark). c-VEMP was recorded unilaterally at the sternocleidomastoid muscle. Surface electromyographic activity was recorded ipsilaterally (Bio-Logic, IL, USA), while the patient was instructed to keep lateral head-turning absolutely in sitting position. The other reference and ground electrodes were separately set on the sternum and forehead. The short tone burst (118 dB HL, $1000 \mathrm{~Hz}, 200$ times per stimulus) was conducted to the unilateral ear through a supra aural headphones (Audiophones, NY, USA). Differences in auditory results between groups were assessed with t-testing and the McNemar test. Statistical significance was set at a $\mathrm{P}$ value of $<0.05$.

\section{Results}

The c-VEMP test results of individuals with unilateral MD and those of healthy persons were compared to establish the baseline information. There were 30 normal-hearing volunteers (17 men and 13 women; age range 23-65 years, mean 30 years). The study population consisted of 42 patients with unilateral involvement of Ménière's disease (16 men and 26 women; age range $26-71$ years, mean 46 years, $\pm 13,17$ ). The DM affecting left ears in 22 and right ears in 20. According AAO-HNS criteria, staging hearing from this group were: 11 patients classified into stage I, 20 patients into stage II, 08 patients into stage III, and 03 patients into stage IV. The clinical average hearing threshold of the diseased ears was $29.8 \pm 15.6 \mathrm{~dB}(4.2-89.7 \mathrm{~dB})$ for the 42 patients. The c-VEMP responses were observed in all controls, and the mean values were: $\mathrm{P} 13=13.66 \mathrm{~ms}( \pm 0.52)$ and $\mathrm{N} 23=23.23 \mathrm{~ms}( \pm 0.95)$; the amplitude asymmetry index $<26.4 \%$, was considered as normal.

For the MD group, the c-VEMP mean values were: P13 $=15.85 \mathrm{~ms}( \pm 0.6), \mathrm{N} 23=23.8 \mathrm{~ms}( \pm 0.38)$; the average asymmetry index was $27.6 \%$. Normal c-VEMP responses were recorded in 25 (59.5\%) patients with DM. Abnormal c-VEMP was recorded in $17(40.5 \%)$. All abnormal responses were found at the same side of the EcoG alteration and hearing loss. From the normal hearing side, c-VEMP abnormalities were not found in all variable, comparing to the control group ( $p>0.05$ ). From the total abnormal responses, P13 latency increase was the most common abnormality, observed in $12(70.6 \%)$ cases. The latency increase P13- N23 wave was observed in 02 (11.8\%) cases. Asymmetry Index abnormality were found in 02 (11.8\%) and one patient presented absence response (5.9\%). The hearing loss stage influenced the number of alterations at the c-VEMP. A higher frequency of them was observed regarding to stage III and IV. These findings can be verified in (Table 1). Distribution between the stage of the hearing loss and the c-VEMP alteration is verified in (Figure 1).

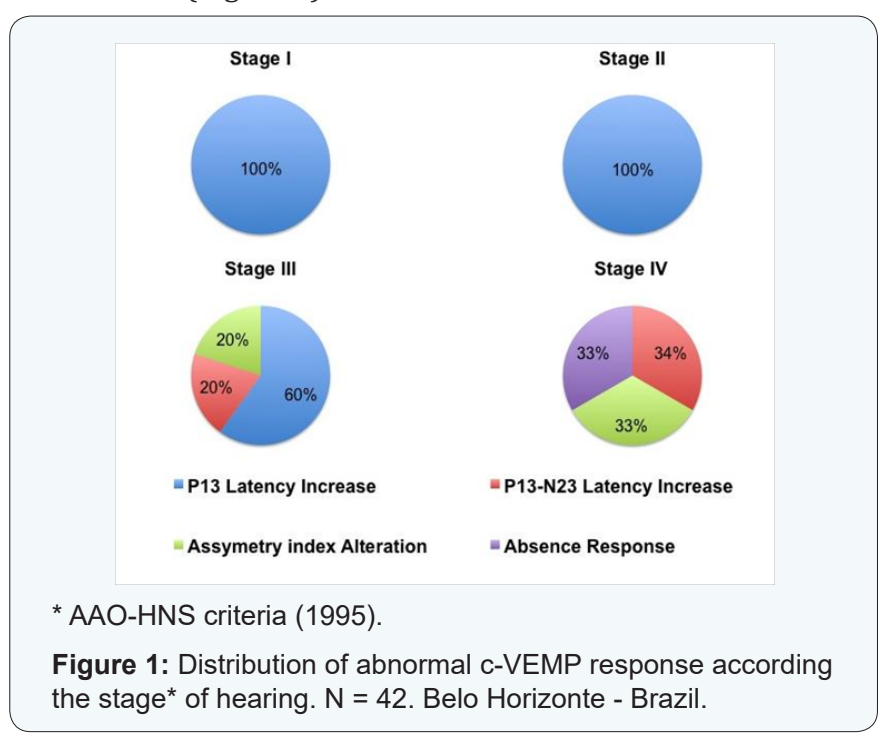




\section{Global Journal of Otolaryngology}

Table 1: Correlation between the stage ${ }^{*}$ of hearing versus normal and abnormal c-VEMP. $\mathrm{N}=42$. Belo Horizonte - Brazil.

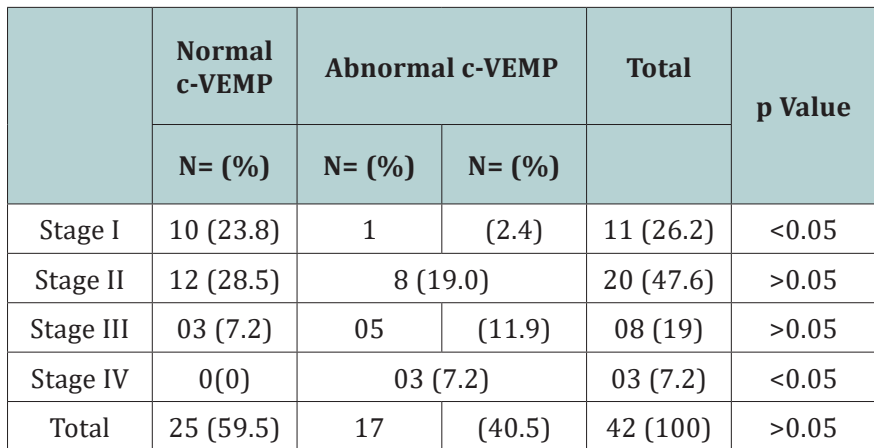

AAO-HNS criteria (1995)

\section{Discussion}

The diagnostic utility of c-VEMP has been investigated in several studies in patients with vestibulocochlear disorders. The presence of a normal c-VEMP implies that the sacculocollic reflex has retained normal conduction velocity; a normal saccule with intact saccular macula [19-22]. According to the literature, saccular dysfunction can be noted as evidenced by either latency increase or absent c-VEMPs on the affected ears 50\%-54\% of the Ménière's patients (ref) Almost half of our patients with MD (40.5\%) reveal abnormal c-VEMPs, indicating saccular involment [12,23-25]. In the early stage of MD, increase latency c-VEMPs may be attributed to a mechanical, bio-chemical, or some other reversible causes, which can be reduced spontaneously or via administration of glycerol or furosemide. However, in the late stage (IV) there are permanent morphological changes in the sense organs, including loss of saccular macula associated with collapse of the saccular wall onto the otolithic membrane, which is consistent with absent c-VEMPs [26-28].

Studies explain the dilated saccule with atrophied saccular macula is characterized by atrophy of the sensory epithelium, partial cellular encapsulation of the otolithic membrane, and a granular basophilic plaque overlying the supporting network of the macular epithelium. The endolymph is displaced more easily in hydropic ears with extended footplate attachment, and this action enhances the sensitivity of the saccular macula to loud sound, resulting in latency delay in c-VEMP $[12,29]$. The hearing loss level influenced the number of alterations in c-VEMP. In the current literature c-VEMP in MD had greater abnormalities in the later stages, corresponding our study where stage III and IV had $62.5 \%$ and $100 \%$, respectively, abnormalities [30].

\section{Conclusion}

c-VEMP would be a useful method for assessing clinical severity or progression of MD, providing complementary information to that obtained by other diagnostic methods.

\section{References}

1. George Gate A (2006) Ménière`s Disease Review 2005. J Am Acad Audiol 17: 16-26.
2. Committee on hering and equilibrium (1995) Committee on Hearing and Equilibrium guidelines for the diagnosis and evaluation of therapy in Meniere's disease. Otolaryngol Head Neck Surg 13(1): 181-185.

3. Semaan MT, Megerian CA (2010) Contemporary perspectives on the pathophysiology of Meniere's disease: implications for treatment Curr Opin Otolaryngol Head Neck Surg 18(5): 392-398.

4. Syed I, Aldren C (2012) Meniere's disease: an evidence based approach to ssessment and management. Int J Clin Pract 66(2): 166-170.

5. Hornibrook J, Kalin C, Lin E O'Beirne GA, Gourley J (2012) Transtympanic Electrocochleography for the Diagnosis of Ménière's Disease. Int J Otolaryngol 85: 271-274.

6. Moon IJ, Park GY, Choi J, Cho YS, Hong SH, et al. (2012) Predictive value of electrocochleography for determining hearing outcomes in Ménière's disease. Otol Neurotol 33(2): 204-210.

7. Vassiliou A, Vlastarakos PV, Maragoudakis P, Candiloros D, Nikolopoulos TP (2011) Meniere's disease: Still a mystery disease with difficult differential diagnosis. Ann Indian Acad Neurol 14(1): 12-18.

8. Magliulo G, Cuiuli G, Gagliardi M, Ciniglio-Appiani G, D’Amico R (2004) Vestibular evoked myogenic potentials and glycerol testing. Laryngoscope 114(2): 338-343.

9. Kingma CM, Wit HP (2011) Asymmetric vestibular evoked myogenic potentials in unilateral Menière patients. Eur Arch Otorhinolaryngol 268(1): 57-61.

10. Okuno T, Sando I (1987) Localization, frequency and severity of endolymphatic hydrops and the pathology of the labyrinthine membrane in Ménière's disease. Ann Otol Rhinol Laryngol Suppl 96(4): 438-445.

11. Merchant SN, Adans JC, Nadol JB (2005) Pathophysiology of Meniere's syndrome: are the symptoms caused by endolymphatic hydrops? Otol Neurotol 26(1): 74-81.

12. Altman F, Kornfeld M (1965) Histological studies of Ménière's disease. Ann Otol Rhinol Laryngol 74(4): 915-943.

13. Colebatch JG, Halmagyi, GM (1992) Vestibular evoked potentials in human neck muscles before and after unilateral vestibular deafferentation. Neurology 42(8): 1635-1636.

14. Ohki M, Matsuzaki M, Sugasawa K, Murofushi T (2002) Vestibular evoked myogenic potentials in ipsilateral delayed endolymphatic hydrops. ORL J Otorhinolaryngol Relat 64(6): 424-428.

15. Seo T, Node M, Yukimasa A, Sakagami M (2003) Furosemide loading vestibular evoked myogenic potential for unilateral Ménière's disease. Otol Neurotol 24(2): 283-288.

16. Felipe L, Santos MAR, Gonçalves DU (2008) Potencial Evocado Miogênico Vestibular (VEMP): avaliação das respostas em indivíduos normais. Pró- Fono 20(4): 249-254.

17. Felipe L, Kingma H, Gonçalves DU (2012) Vestibular evoked myogenic Potential. Int. Arch. Otorhinolaryngol 16(1): 103-107.

18. Súnia Ribeiro, Roberta R de Almeida, Heloisa H Caovilla, Maurício M Ganança (2005) Dos potenciais evocados miogênicos vestibulares nas orelhas comprometida e assintomática na Doença de Ménière unilateral. Rev Bras Otorrinolaringol 71(1): 60-66.

19. Letícia CA Soares, Lara Sílvia O Conegundes, Cláudia Fukuda, Mário Sérgio L Munhoz (2003) Da eletrococleografia transtimpânica em pacientes com e sem hydrops endolinfático e limiares auditivos iguais ou maiores que 50 decibéis. Rev Bras Otorrinolaringol 69(1): 74-82.

20. Timmer FCA, Zhou G, Guinan JJ, Kujawa SG, Hermann BS, et al. (2006) Vestibular evoked myogenic potential (VEMP) in patients with Menière's disease with drop attacks. Laryngoscope 116(5): 776-779. 
21. Murofushi T, Shimizu K, Takegoshi H, Cheng PW (2001) Diagnostic value of prolonged latencies in the vestibular evoked myogenic potential. Arch Otolaryngol Head Neck Surg 127(9): 1069-1072.

22. Rauch SD, Silveira MB, Zhou G, Kujawa SG, Wall C, et al. (2004) Vestibular evoked myogenic potentials versus vestibular test battery in patients with Meniere's disease. Otol Neurotoly 25(6): 981-986.

23. Munhoz MSL (2001) Da sensibilidade e especificidade da eletrococleografia transtimpânica em pacientes com e sem hydrops endolinfático (Tese Livredocência). São Paulo: Universidade Federal de São Paulo. Escola Paulista de Medicina.

24. Letícia CA Soares, Lara Sílvia O Conegundes, Cláudia Fukuda, Mário Sérgio L Munhoz (2003) Da eletrococleografia transtimpânica em pacientes com e sem hydrops endolinfático e limiares auditivos iguais ou maiores que 50 decibéis. Rev Bras Otorrinolaringol 69(1): 74-82.

25. Yong YH, Wu CC, Wu CH (2002) Augmentation of vestibular evoked myogenic potentials: an indication for distended saccular hydrops. Laryngoscope 112(3): 509-512.
26. Kuo S W, Yang TH, Yong YH (2005) Changes in vestibular evoked yogenic potentials after Meniere attacks. Ann Otol Rhinol Laryngol 114(9): 717-721.

27. Kurzina A, Hassmann-Poznanska E, Topolska MM (2005) Effect of the middle ear status on the recording of vestibular evoked myogenic potential - VEMP. Otolaryngol Pol 59(2): 257-262.

28. Rosengren SM, Colebatch JG (2006) Vestibular evoked potentials (VsEPs) in patients with severe to profound bilateral hearing loss. Clin Neurophisiol 117(5): 1145-1153.

29. Lin MY, Timmer FC, Oriel BS, Zhou G, Guinan JJ, et al. (2006) Vestibular evoked myogenic potentials (VEMP) can detect asymptomatic saccular hydrops. Laryngoscope 116(6): 987-992.

30. Davis H, Silverman SR (1970) Auditory Test Hearing Aids. In: Davis H, Silverman SR (Eds), Hearing and Deafness. Rinehart and Winston, Holt, Europe.

Your next submission with JuniperPublishers will reach you the below assets

- Quality Editorial service

- Swift Peer Review

- Reprints availability

- E-prints Service

- Manuscript Podcast for convenient understanding

- Global attainment for your research

- Manuscript accessibility in different formats ( Pdf, E-pub, Full Text, Audio)

- Unceasing customer service

Track the below URL for one-step submission

https://juniperpublishers.com/online-submission.php 